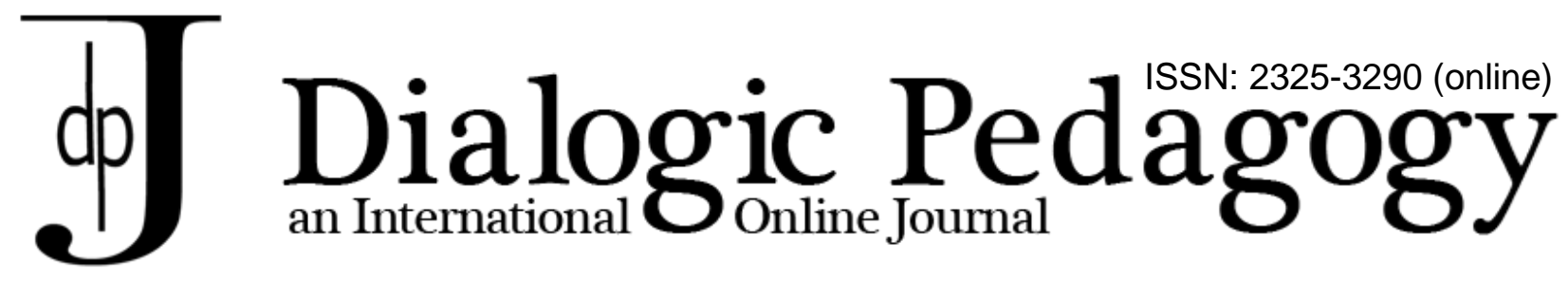

\title{
Wegerif's 21st century advance on dialogic space
}

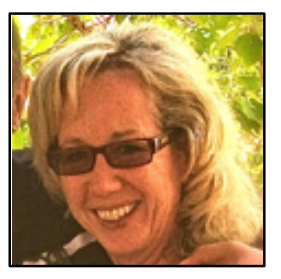

E. Jayne White

University of Waikato, NZ

\begin{abstract}
Book review for Dialogic Pedagogy Journal: Wegerif, R. (2013). Dialogic: Education for the Internet age, London Routledge
\end{abstract}

A timely book indeed, Rupert Wegerif's latest contribution to the field of dialogic pedagogy heralds a new era in education described as "the internet age". Arguing that the Internet disrupts oral and literacy cultures, Wegerif produces a carefully constructed text that sets the scene for a re-visioned look at pedagogy by shifting emphasis from text (literacy) or verbal communication to spatial concepts of glocalisation (a notion that pays attention to the local and the global contexts for learning). From this standpoint he builds a case for education as an open event of being rather than a set of discreet subjects. He does this through the route of dialogism. I think that Bakhtin would be most pleased to see his work brought into this contemporary space through an interanimation of theory and practice - both traditional and contemporary.

What strikes the reader throughout this book is the expansive view Wegerif takes to the application of dialogism to education. He draws from contemporary fields of understanding such as neurological science, educational practice in virtual and real classrooms, and philosophy. No stone is unturned in this regard as the reader is drawn into familiar and unfamiliar terrain ranging from the traditions of Socrates, to Oakeshott's contemporary notion of 'conversation of mankind' - each are critically considered as contributors to Wegerif's interpretation of dialogic pedagogy and its contemporary significance. Of particular note is the fruitful attention paid to Buber's "I-thou", as an alliance with Bakhtin's dialogic imperatives; and to Merleau-Ponty's "chiasm" as a means of expanding Bakhtin's authorial position of insider-outsider. Taken together, these allegiances provide points of connection and, in doing so, expand on dialogic principles and their application to the internet by purporting for education that is unbounded, spatially complex and connected to others - seen and unseen. In this conceptualisation education is no longer limited to classroom, individual, dyad or even culture, but represents an opportunity to engage in difference as a route to creativity.

Notwithstanding the important contribution to education and the Internet, Wegerif provides a remarkable synthesis of dialogic pedagogy in this book. In perhaps the most comprehensive text I have read on the subject, dialogic pedagogy is summarised as "education for dialogue as well as through dialogue in which dialogue is not only treated as a means to an end but also treated as an end in itself" ( $p$. 
33). In accordance with this view, Wegerif offers a means of thinking about dialogue as a way of opening, widening and deepening space. Here he offers specific pedagogical strategies such as reflective questioning, bringing in new voices and challenging assumptions through processes such as deconstruction, degrees of difference, intersubjectivity and self-hood. An important contribution to the field, in this regard, is the shift from individuals and even cultures to pay attention to Bakhtin's 'superaddressee' (also Levinas' 'Infinite Other') and the significance of silent voices in dialogues. The important point is made here that dialogue is at its best when there are gaps and differences. Wegerif provides several examples from his own research and (to a lesser extent) that of others in the field, to embellish this idea. In doing so he provides significant and much needed challenge to sociocultural strongholds in education that, according to this view, limit learning to a particular setting, agenda or domain. His attention to modern technologies as a way of engaging with other, through the use of avatars, blogs and Facebook, suggest that there is much potential in this regard.

Perhaps the greatest contribution this book makes, for any teacher or learner, is in the simple pedagogical message that dialogues alone do not make a difference. Learning takes place in terms Wegerif borrows from neuroscience, Global Workspace Theory and Kant's transcendence principle that are aligned to consciousness. "Consciousness is not only the lit up stage at the centre of the theatre but includes the audience," says Wegerif (p. 156). According to this principle meaning is found in relationship with other (people, spaces and concepts) only when one is able to make sense of what they experience. Thus meaning exists in encounters that exist well beyond the immediate context or time; they also take place in the unconscious (or sentient) spaces of experience. Wegerif calls upon contemporary early years research to exemplify the claim that dialogic experience of this nature is central to learning. His attention to connected thinking of human beings as a requisite for creativity offers a stark contrast to the impact of scientism that Wegerif argues against in contemporary education, suggesting it is "not a fixed world of stable things but more like a horizon cast by a gaze" (p. 160). Here Wegerif invokes Bakhtins notion of "great time" as a means of interpreting the experience of dialogue for learning in the global community that characterises the Internet. In this regard, the reader is invited to contemplate the affordances offered in this unbounded space. Thus, the book takes us full circle, since the unbounded space of the Internet sets the scene for dialogic ways of teaching. Wegerif concludes by asking the perilous question "what, then, and how should we teach" and completes his insightful analysis by calling for greater attention to the explicit methods of dialogue itself - critical, creative thinking, collaboration and communication. In essence, Wegerif suggests that to be an effective teacher one must learn to be an effective learner.

This book offers an important challenge to educators who frequently struggle to work with learners who are natives in the digital era, when they themselves are not. Classrooms continue to be conceptualised typically as a building space with desks, bells and set curriculum yet Wegerif proposes a very different view. His challenge is salved by numerous examples of possible practice, building on what is already known to educators and gently pushing the field into this new era. I suspect this book heralds the advent of educational research as well as practice that foregrounds dialogue in the contexts of consciousness, creativity, science and technology. In this, there are multiple provocations for all and I, for one, look forward to exploring these in the wake of this fabulous contribution to the field.

(c) $)$ EY

Articles in this journal are licensed under a Creative Commons Attribution 3.0 United States License. 


\section{ULIS D-Sont}

This journal is published by the University Library System, University of Pittsburgh as part of its D-Scribe Digital Publishing Program and is cosponsored by the University of Pittsburgh Press. 